\title{
Development and Validation of a Novel RP-HPLC Method for Estimation of Losartan Potassium in Dissolution Samples of Immediate and Sustained Release Tablets
}

\author{
Harshal A. Pawar ${ }^{1}$ and K. G. Lalitha ${ }^{2}$ \\ ${ }^{1}$ Research Scholar, Ultra College of Pharmacy, 4/235 College Road, Thasildar Nagar, Madurai, Tamil Nadu 625020, India \\ ${ }^{2}$ Department of Pharmaceutical Chemistry, Ultra College of Pharmacy, 4/235, College Road, Thasildar Nagar, \\ Madurai, Tamil Nadu 625020, India \\ Correspondence should be addressed to Harshal A.Pawar; hapkmk@rediffmail.com
}

Received 26 October 2013; Accepted 11 March 2014; Published 9 April 2014

Academic Editor: Irene Panderi

Copyright (C) 2014 H. A. Pawar and K. G. Lalitha. This is an open access article distributed under the Creative Commons Attribution License, which permits unrestricted use, distribution, and reproduction in any medium, provided the original work is properly cited.

\begin{abstract}
A simple, rapid, selective, and reproducible reversed-phase high performance liquid chromatographic (RP-HPLC) method has been developed and validated for the estimation of Losartan potassium in dissolution samples of Losartan potassium immediate and sustained release tablets. Analysis was performed on an Agilent, Zorbax Eclipse XDB $\mathrm{C}_{18}$ column $(150 \mathrm{~mm} \times 4.6 \mathrm{~mm}, 5 \mu \mathrm{m})$ with the mobile phase consisting of orthophosphoric acid $(0.1 \% \mathrm{v} / \mathrm{v})$-acetonitrile $(55: 45, \mathrm{v} / \mathrm{v})$ at a flow rate of $1.0 \mathrm{~mL} / \mathrm{min}$. UV detection was performed at $225 \mathrm{~nm}$ and the retention time for Losartan was about 2.6 minutes. The calibration curve was linear (correlation coefficient $=0.999$ ) in the selected range of analyte. The optimized dissolution conditions include the USP apparatus 2 at a paddle rotation rate of $50 \mathrm{rpm}$ and $900 \mathrm{~mL}$ of $\mathrm{pH} 6.8$ phosphate buffer as dissolution medium, at $37.0 \pm 0.5^{\circ} \mathrm{C}$. The method was validated for precision, linearity, specificity, accuracy, limit of quantitation, and ruggedness. The system suitability parameters, such as theoretical plate, tailing factor and relative standard deviation (RSD) between five standard replicates, were well within the limits. The stability result shows that the drug is stable in the prescribed dissolution medium.
\end{abstract}

\section{Introduction}

Dissolution is an official test routinely used in Quality Control (QC) and Research and Development (R and D) Laboratories for the evaluation of pharmaceutical products. The purpose of in vitro dissolution studies in QC is to check batch to batch consistency and detection of manufacturing deviation while in $\mathrm{R}$ and $\mathrm{D}$ the focus is to provide some predictive estimate of the drug release in respect to the in vivo performance of a drug product [1].

Losartan potassium is chemically 2-butyl-4-chloro1-[p-(o-1H-tetrazol-5-yl-phenyl)benzyl]-imidazole-5methanol monopotassium salt (Figure 1) [2]. It is an angiotensin II receptor blocker and chemically is used as an antihypertensive agent [3]. Losartan has been demonstrated to be superior to previous peptide receptor antagonists and angiotensin converting enzyme (ACE) inhibitors because of its enhanced specificity, selectivity, and tolerability
[4]. Currently, Losartan potassium is marketed alone or combined with hydrochlorothiazide.

Several analytical methods have been applied to the analysis of Losartan potassium in pharmaceutical products that make use of high performance thin layer chromatography (HPTLC) [5, 6], capillary electrophoresis (CE), capillary electrochromatography (CEC) [7], and spectrophotometry [8-10]. The literature reports many analytical methods for the quantitation of Losartan in tablets using HPLC [11-15]. All these reported methods either took a long time for analysis or employ mobile phases with $\mathrm{pH}$ adjustment of buffer solutions which is tedious and not suitable, especially for routine testing of quality control samples of dissolution study. Hence, this project was undertaken with an intention to develop a rapid analytical method for the estimation of Losartan potassium in dissolution samples to support product development and quality control efforts. 


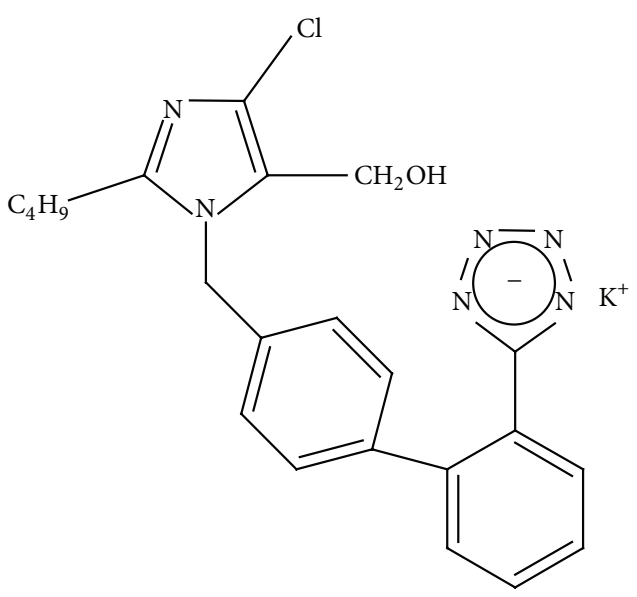

Figure 1: Chemical structure of Losartan potassium [28].

This paper described a new RP-HPLC method for the estimation of Losartan potassium in dissolution samples using simple mobile phase. The objective of the present study was to develop a simple, less time consuming and, economical analytical method for estimation of Losartan potassium in dissolution study of its formulation. The proposed method was validated as per ICH guidelines [16-18].

\section{Experimental}

2.1. Chemicals and Reagents. Losartan potassium reference substance was obtained as a gift sample from Flamingo Pharmaceutical Ltd., Taloja. HPLC grade water and solvents were used for HPLC analysis. All the buffer solutions were prepared according to the procedure given in the US Pharmacopoeia.

2.2. Instrumentations. Agilent 1100 series integrated high performance liquid chromatographic system equipped with quaternary pump, manual sampler, variable wavelength detector, and column thermostat was used for HPLC analysis. The Zorbax Eclipse XDB C $18(4.6 \times 150 \mathrm{~mm}, 5 \mu \mathrm{m})$ analytical column was used as a stationary phase. Chromatographic data was acquired using ChemStation software. All dissolution experiments were carried out using a dissolution instrument Electrolab TDT-08L (Electrolab, India).

\subsection{Methodology}

2.3.1. Determination of Solubility and Dissolution Optimization. The dissolution characteristics of an oral formulation should be evaluated in the physiologic $\mathrm{pH}$ range of 1.2-6.8. Losartan potassium solubility was determined using $900 \mathrm{~mL}$ of purified water, $0.1 \mathrm{~N}$ hydrochloric acid, acetate buffer $(\mathrm{pH}$ 1.2, 2.1, and 5.5), and phosphate buffer ( $\mathrm{pH}$ 6.8) with an amount of drug equivalent to three times of the dose in the pharmaceutical formulation as per the method specified in US Pharmacopoeia, 2007 [19]. Based on solubility results for Losartan potassium in each dissolution medium tested and considering a test volume of $900 \mathrm{~mL}$ per vessel, sink conditions were verified.

From preselected $\mathrm{pH} 6.8$ phosphate buffer media, dissolution testing was performed on tablet $(n=6)$ in compliance with USP $\langle 711\rangle$ using paddle (USP-II) [20]. The discriminatory power of the dissolution method was assessed by analyzing two in-house developed immediate release formulations of Losartan potassium tablet (coded as Product-A and Product-B) of $50 \mathrm{mg}$ strength prepared by using different composition of excipients. Product-A contains $5 \%$ pregelatinized starch as a disintegrant whereas ProductB contains $10 \%$ pregelatinized starch as a disintegrant. Other excipients include lactose (anhydrous), microcrystalline cellulose, and magnesium stearate. The developed method was also tested for the dissolution of in-house prepared Losartan potassium sustained release matrix tablets (coded as ProductC, strength: $50 \mathrm{mg}$ ).

A calibrated dissolution apparatus (USP II) was used with paddles at $50 \mathrm{rpm}$ and bath temperature maintained at $37 \pm 0.5^{\circ} \mathrm{C}$. Nine hundred milliliter freshly prepared and degassed pH 6.8 phosphate buffer solution was used as the dissolution medium. Dissolution samples were collected at $15,30,45$, and $60 \mathrm{~min}$ for immediate release tablets (ProductA and Product-B) and $1 \mathrm{hr}, 2 \mathrm{hr}, 4 \mathrm{hr}, 6 \mathrm{hr}, 8 \mathrm{hr}, 10 \mathrm{hr}, 12 \mathrm{hr}$, $16 \mathrm{hr}, 20 \mathrm{hr}$, and $24 \mathrm{hr}$ for sustained release matrix tablets (Product-C). At each time point, a $5 \mathrm{~mL}$ sample was removed from each vessel, filtered through a nylon filter $(0.45 \mu \mathrm{m}$, $25 \mathrm{~mm}$ ) into labeled glass tubes, and analyzed by HPLC. The amount of Losartan potassium in the test samples was calculated, as percentage dissolved, from the measured peak area for the test samples and standard solution. The assay of the above three products (A, B, and $\mathrm{C}$ ) was performed using previously validated spectrophotometric method, and the results obtained were used to calculate the percentage release on each time of dissolution profile.

2.3.2. Instrumentation and Chromatographic Conditions. RPHPLC method was used to analyze the Losartan potassium tablet samples in $\mathrm{pH} 6.8$ phosphate buffer as dissolution medium. An Agilent 1100 series HPLC (Wilmington, DE, USA) which consisted of a quaternary pump, an automatic injector, a variable wavelength detector, and a column oven was used for analysis. Data was collected using Agilent ChemStation software. An isocratic HPLC analysis was performed on Agilent Zorbax XDB C $18(150 \times 4.6 \mathrm{~mm}, 5 \mu \mathrm{m})$ column maintained at ambient condition $\left(25^{\circ} \mathrm{C}\right)$. Chromatographic separation was achieved with the mobile phase ratio of 55: $45(\mathrm{v} / \mathrm{v})$ mixture of orthophosphoric acid $(0.1 \% \mathrm{v} / \mathrm{v})$ and acetonitrile at a flow rate of $1.0 \mathrm{~mL} / \mathrm{min}$. The column temperature was controlled at $25^{\circ} \mathrm{C}$ and the injection volume was $20 \mu \mathrm{L}$. The UV detection wavelength was $225 \mathrm{~nm}$.

2.3.3. Preparation of Standard Solutions. Losartan potassium stock solution was prepared in $\mathrm{pH} 6.8$ phosphate buffer and sonicated for $10 \mathrm{~min}$ to obtain stock solution concentrations of $1000 \mu \mathrm{g} / \mathrm{mL}$. From this stock solution, $5.5 \mathrm{~mL}$ was transferred to $100 \mathrm{~mL}$ volumetric flask and diluted to volume with dissolution media to obtain a solution of $55 \mu \mathrm{g} / \mathrm{mL}$. 
2.3.4. Analytical Method Development and Validation. In the current study, RP-HPLC method was used to determine the percentage of drug release. The HPLC parameters were optimized on trial and error basis. The developed method was validated for precision, linearity, specificity, accuracy, limit of quantitation, and ruggedness according to US-FDA and ICH (International Conference on Harmonization) guideline $[21,22]$.

2.3.5. Evaluation of System Suitability. System suitability was determined from five replicate injections (twenty microliters each) of the standard solution before the analysis and the chromatograms were recorded. Relative standard deviation (RSD) of peak area for five replicates of standard was calculated. System suitability parameters like symmetry, theoretical plate, and tailing factor were also recorded. The acceptance criteria were less than 2\% RSD for peak area, greater than 2000 column plates and USP tailing factor less than 1.5 .

2.3.6. Specificity. Specificity was evaluated by preparing samples of placebo consisted of mixture of all the excipients. The samples of the placebo were transferred to separate vessels $(n=3)$, filled with $900 \mathrm{~mL}$ of dissolution medium at $37 \pm$ $0.5^{\circ} \mathrm{C}$, and stirred for $1 \mathrm{~h}$ at $150 \mathrm{rpm}$. Aliquots were withdrawn and analyzed by HPLC.

2.3.7. Linearity and Range. A stock solution containing $1000 \mu \mathrm{g} / \mathrm{mL}$ of Losartan potassium was prepared in $\mathrm{pH} 6.8$ phosphate buffer. The linearity of the method was evaluated in the $5.5-104.5 \mu \mathrm{g} / \mathrm{mL}$ range using stock solution and dissolution medium. The solutions were injected in triplicate. The mean peak area versus concentration data was treated by least-squares linear regression analysis.

2.3.8. Accuracy. Accuracy refers to the closeness of a measured value to a standard or known value. Accuracy is usually reported as percent recovery by an assay using the proposed analytical procedure of known amount of analyte added to the sample. The ICH guidelines also recommended assessing a minimum of three determinations over a minimum of three concentration levels covering the specified range. Accuracy of the dissolution method was calculated by recovery studies at three concentrations of $80 \%, 100 \%$, and $120 \%$ levels by standard addition method.

Accuracy was accomplished by adding known amounts of Losartan potassium reference substance to placebo. Aliquots of $4.0,5.0$, and $6.0 \mathrm{~mL}$ of a $10 \mathrm{mg} / \mathrm{mL}$ Losartan potassium standard solution dissolved in $\mathrm{pH} 6.8$ phosphate buffer were added to vessels containing dissolution medium for a final volume of $900 \mathrm{~mL}$ (final concentrations were $44.44 \mu \mathrm{g} / \mathrm{mL}$, $55.56 \mu \mathrm{g} / \mathrm{mL}$, and $66.67 \mu \mathrm{g} / \mathrm{mL}$, resp.), preheated at $37^{\circ} \mathrm{C}$, and rotated for $1 \mathrm{~h}$ at $150 \mathrm{rpm}$. Aliquots were withdrawn and analyzed by HPLC.

2.3.9. Precision. Intraday precision and intermediate precision were done for ensuring the ruggedness of the method. Intraday and intermediate precision were determined by
TABLE 1: Quantitative solubility of Losartan potassium in different medium.

\begin{tabular}{lcc}
\hline Dissolution medium & Solubility in $\mathrm{mg} / \mathrm{mL}^{\mathrm{a}}$ & S.D. \\
\hline Purified water & 97.058 & 0.09 \\
$0.1 \mathrm{~N} \mathrm{HCl}$ & 4.573 & 0.02 \\
pH 1.2 acetate buffer & 4.585 & 0.01 \\
pH 2.1 acetate buffer & 6.170 & 0.02 \\
pH 5.5 acetate buffer & 6.261 & 0.03 \\
pH 6.8 phosphate buffer & 93.457 & 0.03 \\
\hline
\end{tabular}

${ }^{\mathrm{a}}$ Mean of three determinations; S.D.: standard deviation.

analyzing the solutions on different days using multiple lots of column. A minimum six determinations at $100 \%$ of the standard concentration were tested to find out the mean, standard deviation and relative standard deviation.

2.3.10. Robustness. The robustness of the method was evaluated by analyzing the system suitability standard and evaluating system suitability parameter data after varying, individually, the HPLC pump flow rate $( \pm 0.2 \mathrm{~mL} / \mathrm{minute})$, detection wavelength $( \pm 2 \mathrm{~nm})$, and column compartment temperature $\left( \pm 5^{\circ} \mathrm{C}\right)$.

2.3.11. Stability Studies. Stability of Losartan potassium in the selected dissolution medium ( $\mathrm{pH} 6.8$ phosphate buffer) was evaluated using standard and sample. The solutions were kept at $37 \pm 0.5^{\circ} \mathrm{C}$ for $24 \mathrm{hr}$ under light shaking as well as at room temperature for $24 \mathrm{hr}$ (the sample solution was stored in a glass test tube wrapped securely in paraffin). Aliquots of the samples were tested at time 0 and after every $1 \mathrm{hr}$ till $24 \mathrm{hr}$. The responses for the aged solutions were evaluated using a freshly prepared standard. The analysis was performed in triplicate.

\section{Results and Discussion}

3.1. Optimization of Dissolution Test Conditions. The phosphate buffer $(\mathrm{pH}$ 6.8) and water provided highest solubility with greater stability, ensuring excellent sink conditions (Table 1).

Purified water is often used as the dissolution medium but is not ideal for several reasons. First, the quality of the water can vary depending on the source of the water, and the $\mathrm{pH}$ value of the water is not controlled. Second, the $\mathrm{pH}$ value can vary from day to day and can also change during the run, depending on the active substance and excipients [23]. Hence, pH 6.8 phosphate buffer was selected as the best dissolution medium. Also the stability test indicated that Losartan potassium is stable in the $\mathrm{pH} 6.8$ phosphate buffer at room temperature and at $37.0 \pm 0.5^{\circ} \mathrm{C}$ for $24 \mathrm{hr}$. Based on the solubility, stability, and sink condition, $\mathrm{pH} 6.8$ phosphate buffer was selected as the dissolution medium and USP type 2 rotating paddle apparatus at $50 \mathrm{rpm}$ as an instrument.

The in vitro release profile $(n=6)$ of in-house developed immediate release formulation (Product-A and Product-B) 


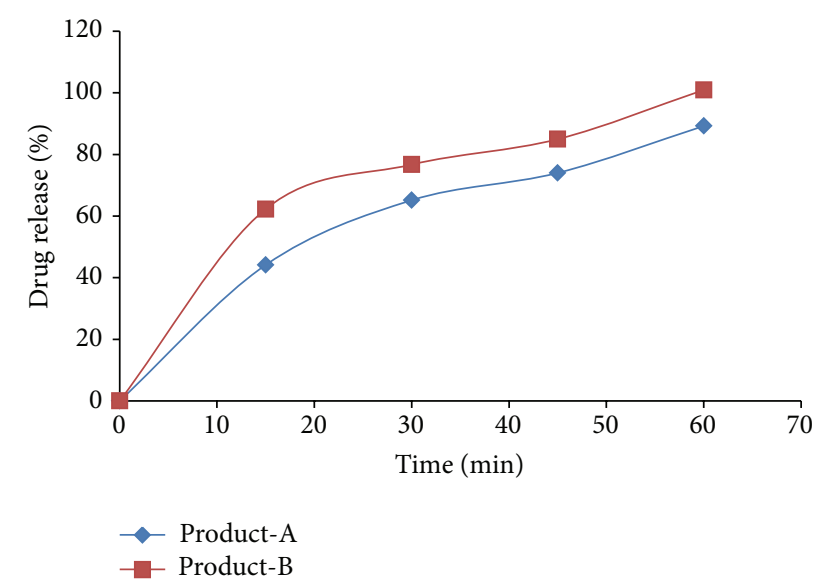

FIGURE 2: In vitro release profile $(n=6)$ of immediate release tablets (Product-A and Product-B) of Losartan potassium.

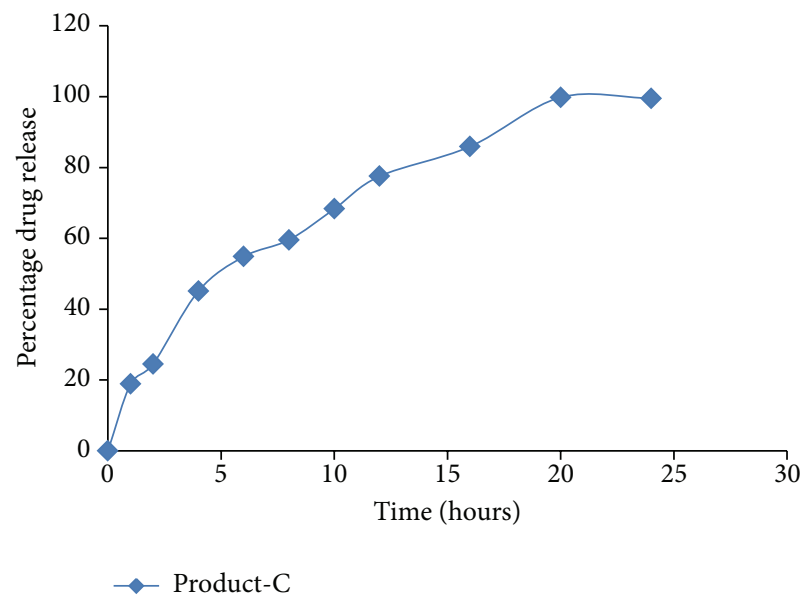

FIGURE 3: In vitro release profile $(n=6)$ of sustained release matrix tablets (Product-C) of Losartan potassium.

and sustained release formulation (Product-C) of Losartan potassium is represented in Figures 2 and 3, respectively.

The discriminating power of the dissolution method is the method's ability to detect changes in the drug product [24-26]. The dissolution profiles obtained for Product-A and Product-B were compared using model-independent method, in which the two profiles were compared only at the observed time points [27]. The model-independent approach includes the difference factor $\left(f_{1}\right)$ and the similarity factor $\left(f_{2}\right)$. According to the FDA, two dissolution profiles are declared similar if $f_{1}$ is between 0 and 15 and if $f_{2}$ is between 50 and 100 [21]. The results confirmed that the profiles obtained are not similar (Table 2).

3.2. Optimization of HPLC Method. As the dissolution test is the routine test that needs to be performed for each batch of the product, the quality control labs are always overburdened with dissolution samples. Hence, it is a real challenge to the development scientist to develop rapid analytical method for dissolution testing to complete the analysis in reasonable
TABle 2: Comparison of dissolution profiles of Product-A and Product-B.

\begin{tabular}{lc}
\hline Parameter & Result obtained \\
\hline$f 1$ (similarity factor) & 16.1 \\
$f 2$ (difference factor) & 43.6 \\
\hline
\end{tabular}

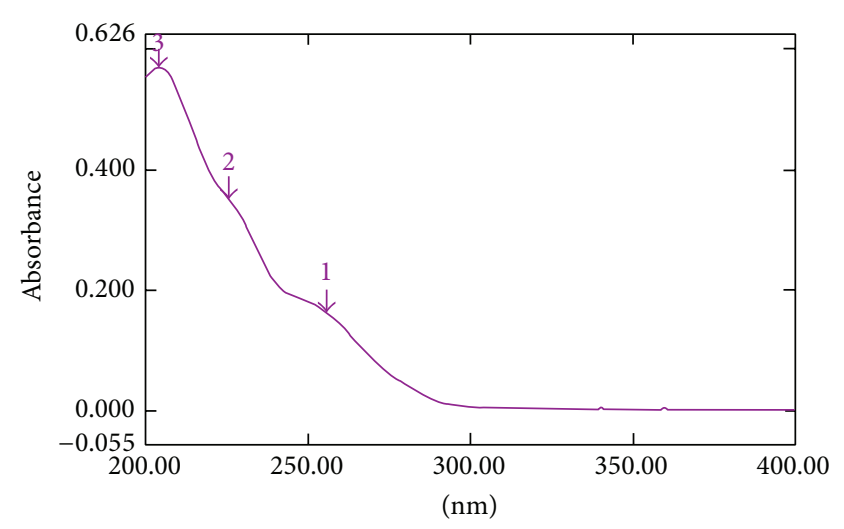

FIGURE 4: UV spectrum of Losartan potassium.

period of time. Since the drug was polar, we started the development with reverse phase chromatography. We tried $\mathrm{RP}^{-\mathrm{C}_{8}}$ and $\mathrm{RP}-\mathrm{C}_{18} \mathrm{HPLC}$ columns with different specifications and manufacturers. Agilent Zorbax XDB (150 mm $\times 4.6 \mathrm{~mm}, 5 \mu \mathrm{m})$ has given better peak shape with short retention time. UV spectrum of Losartan potassium showed maximum absorbance at $205 \mathrm{~nm}, 225 \mathrm{~nm}$, and $254 \mathrm{~nm}$ wavelength (Figure 4). Better peak response and less placebo interference were observed at $225 \mathrm{~nm}$. Considering the $\mathrm{p} K_{a}$ value of Losartan potassium, we tried $\mathrm{KH}_{2} \mathrm{PO}_{4}, \mathrm{~K}_{2} \mathrm{HPO}_{4}$, and $0.1 \% \mathrm{v} / \mathrm{v}$ orthophosphoric acid as mobile phases in combination with methanol as well as acetonitrile in different ratio with isocratic elution. Peak shape was not proper when methanol was used as a component of mobile phase. Hence, methanol was replaced with acetonitrile. The good performance with rapid elution was achieved in mobile phase consisting of orthophosphoric acid $(0.1 \% \mathrm{v} / \mathrm{v})$ and acetonitrile (55: $45, \mathrm{v} / \mathrm{v})$ at a flow rate of $1.0 \mathrm{~mL} / \mathrm{min}$.

\subsection{Analytical Method Validation}

3.3.1. System Suitability. System suitability is an important parameter to ensure whether the used method was valid or not. The system suitability assessment for the analytical HPLC method established instrument performance parameters such as retention time, peak area (\%RSD), symmetry, theoretical plates, and USP tailing factor for Losartan peak. All critical parameters tested met the acceptance criteria on all days (Table 3).

3.3.2. Specificity. According to the Pharmacopoeial Forum and USP 32 [21, 25], the lack of chromatographic peaks from the placebo formulation demonstrates the specificity of the method. No chromatographic peak from the placebo formulation was observed at the retention time of Losartan 


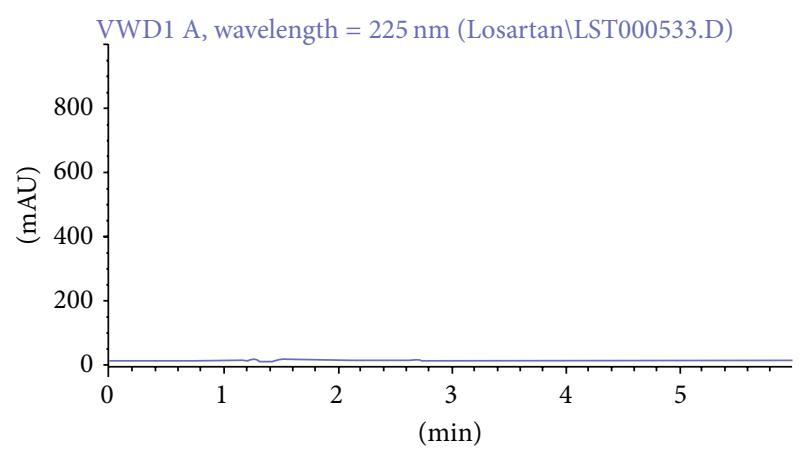

FIGURE 5: Representative chromatogram of placebo.

TABLE 3: System suitability test results.

\begin{tabular}{lcccc}
\hline Parameters & Specifications & Day 1 & Day 2 & Day 3 \\
\hline Retention time (\% RSD) & $\leq 2.0$ & 0.23 & 0.32 & 0.29 \\
Symmetry & $\leq 2.0$ & 0.92 & 0.97 & 0.94 \\
Area (\% RSD) & $\leq 2.0$ & 0.97 & 0.87 & 0.89 \\
Theoretical plates (column) & $>2000$ & 7878 & 7804 & 7858 \\
USP tailing & $<2.0$ & 1.049 & 1.043 & 1.039 \\
\hline
\end{tabular}

TABLE 4: Linear regression of Losartan potassium.

\begin{tabular}{lc}
\hline Concentration $(\mathrm{mcg} / \mathrm{mL})$ & Area $^{\mathrm{a}}(\mathrm{mAU})$ \\
\hline 5.5 & 323.88911 \\
16.5 & 990.68721 \\
33 & 2205.75408 \\
44 & 2952.47113 \\
55 & 3842.69317 \\
66 & 4544.43515 \\
82.5 & 5726.98713 \\
104.5 & 7260.89909 \\
\hline Slope & 70.72 \\
Intercept & -116.9 \\
Correlation coefficient $\left(R^{2}\right)$ & 0.999 \\
\hline
\end{tabular}

${ }^{a}$ Average of three determinations.

in the placebo chromatogram (Figure 5). The representative chromatogram of standard and sample is shown in Figures 6 and 7 , respectively.

3.3.3. Linearity and Range. To validate linearity, the standard curve of Losartan was constructed by plotting concentration $(\mathrm{mcg} / \mathrm{mL})$ versus area response $(\mathrm{mAU})$ which is shown in Figure 8 . The linear regression and slope were calculated and are shown in Table 4 . The linearity of Losartan response showed a good correlation coefficient $\left(r^{2}\right)=0.999$. Range was set by establishing acceptable precision, accuracy, and linearity over the analytical range from 5.5 to $104.5 \mu \mathrm{g} / \mathrm{mL}$.

3.3.4. Accuracy. Accuracy of the dissolution method was calculated by recovery studies at three concentrations of $80 \%$, $100 \%$, and $120 \%$ levels by standard addition method. The mean percentage recoveries (accuracy) obtained were found

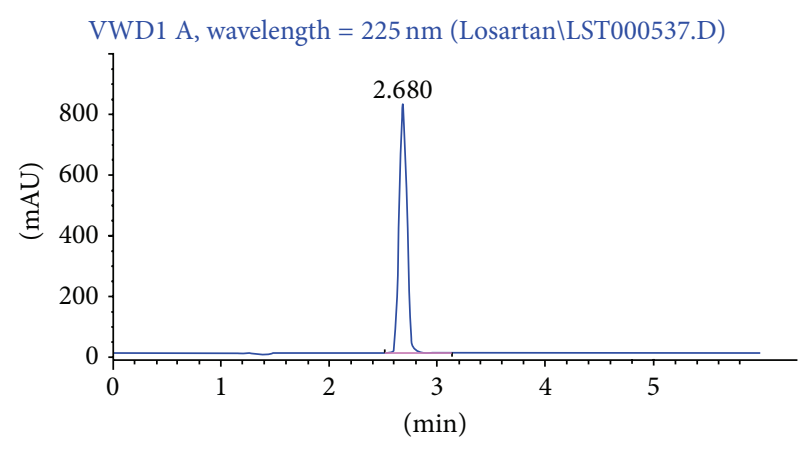

FIGURE 6: Representative chromatogram of standard.

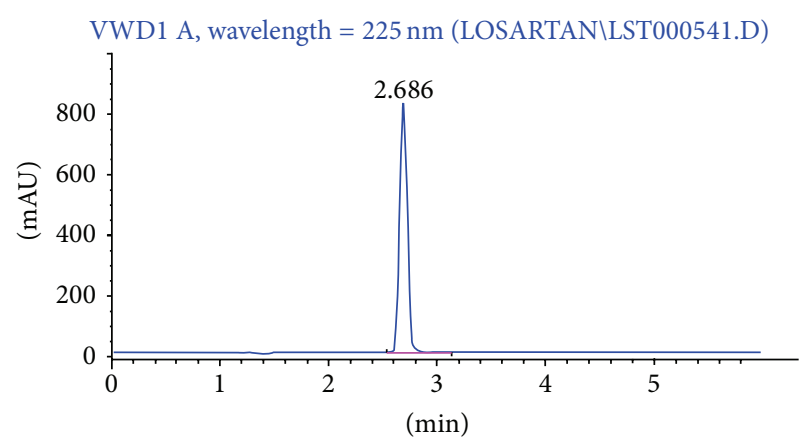

FIGURE 7: Representative chromatogram of sample.

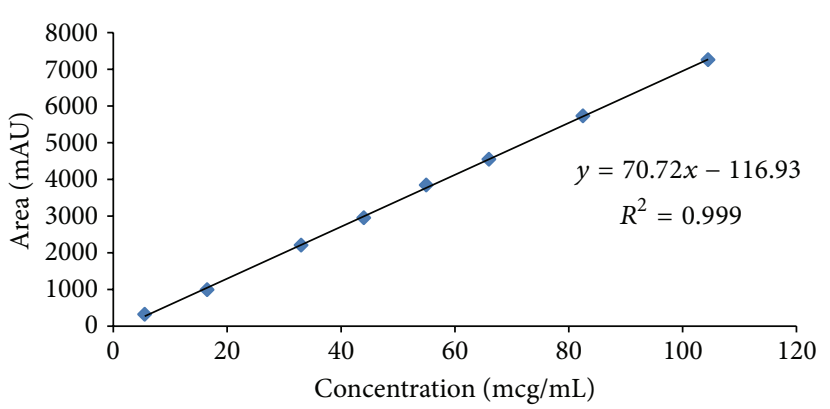

FIGURE 8: Linearity graph of Losartan potassium.

between $95 \%$ and $105 \%$. The results of recovery study are summarized in Table 5.

3.3.5. Precision. The precision of an analytical procedure expresses the closeness of the agreement (degree of scatter) between a series of measurements obtained from the multiple samples of the same homogeneous sample under the prescribed conditions. The percentage RSD obtained under different conditions was below 2\%. Table 6 represents the results of intermediate and intraday precision. The relative standard deviation (RSD) of both the tests was well within the desirable limit of NMT $2.0 \%$ which clearly indicates that the developed method is rugged.

3.3.6. Robustness. In order to demonstrate the robustness of the assay method, system suitability parameters were 
TABLE 5: Results of Accuracy study.

\begin{tabular}{|c|c|c|c|c|c|c|c|}
\hline Concentration Levels (\%) & Area $^{\mathrm{a}}$ & Weight Spiked in mg & Weight Recovered in $\mathrm{mg}$ & Accuracy (\%) & Mean & S.D. & \% R.S.D. \\
\hline \multirow{3}{*}{80} & 3253.93481 & 40 & 39.69 & 99.23 & \multirow{3}{*}{98.69} & \multirow{3}{*}{0.697} & \multirow{3}{*}{0.71} \\
\hline & 3243.92433 & 40 & 39.57 & 98.92 & & & \\
\hline & 3210.32104 & 40 & 39.16 & 97.90 & & & \\
\hline \multirow{3}{*}{100} & 4011.84668 & 50 & 48.94 & 97.87 & \multirow{3}{*}{98.30} & \multirow{3}{*}{0.704} & \multirow{3}{*}{0.72} \\
\hline & 4062.57153 & 50 & 49.56 & 99.11 & & & \\
\hline & 4013.37207 & 50 & 48.96 & 97.91 & & & \\
\hline \multirow{3}{*}{120} & 4851.41895 & 60 & 59.18 & 98.63 & \multirow{3}{*}{98.64} & \multirow{3}{*}{0.301} & \multirow{3}{*}{0.30} \\
\hline & 4867.05420 & 60 & 59.37 & 98.95 & & & \\
\hline & 4837.47510 & 60 & 59.01 & 98.35 & & & \\
\hline
\end{tabular}

S.D.: Standard deviation; R.S.D.: Relative standard deviation.

${ }^{a}$ Average of three determinations.

TABLE 6: Results of intermediate and intraday precision.

\begin{tabular}{lcccc}
\hline Replicates & Day 1 (area) & Day 2 (area) & Column I (area) & Column II (area) \\
\hline Area 1 & 4008.94702 & 4022.12301 & 4067.21134 & 4054.66455 \\
Area 2 & 3986.29590 & 4006.95633 & 3956.54367 & 4036.49724 \\
Area 3 & 3946.11646 & 3977.66754 & 3998.43554 & 3986.98756 \\
Area 4 & 4029.71875 & 3989.07986 & 4009.46983 & 3992.43927 \\
Area 5 & 4052.51440 & 4044.43532 & 4032.44356 & 4049.87234 \\
Area 6 & 4025.62451 & 4065.12433 & 3988.54437 & 3995.05438 \\
\hline Average & 4008.20284 & 4017.56440 & 4008.77472 & 3019.25256 \\
Standard deviation & 37.590 & 33.228 & 37.999 & 31.095 \\
RSD & 0.94 & 0.83 & 0.95 & 0.77 \\
\hline Average & \multicolumn{5}{c}{4014.01364} \\
Standard deviation & 4012.88362 & 32.157 \\
RSD & 32.747 & & 0.80 \\
\hline
\end{tabular}

RSD: relative standard deviation.

TABLE 7: Factors of robustness study.

\begin{tabular}{lccc}
\hline Parameter & Low & Nominal & High \\
\hline Wavelength $(\mathrm{nm})$ & 223 & 225 & 227 \\
Flow rate $(\mathrm{mL} / \mathrm{min})$ & 0.8 & 1.0 & 1.2 \\
Temperature $\left({ }^{\circ} \mathrm{C}\right)$ & 20 & 25 & 30 \\
\hline
\end{tabular}

evaluated in the study as shown in Table 7 and include wavelength, flow rate, and column temperature.

The most important factors that affect peak asymmetry are flow rate and temperature. The method, however, is robust with respect to peak asymmetry; this value was consistent $<1.2$ across all values of these parameters. Method suitability, therefore, will not be adversely affected with respect to peak asymmetry.

Flow rate is the parameter that significantly affects peak efficiency. The method, however, is robust with respect to peak efficiency; this value was consistent $>2000$ across all values of these parameters. Method suitability, therefore, will not be adversely affected with respect to peak efficiency.

3.3.7. Limit of Quantitation. Limit of quantitation (LOQ) is the lowest amount of analyte in a sample that can be determined with acceptable precision and accuracy under stated experimental conditions. The quantitation limit is expressed as the concentration of analyte in the sample. The standard deviation and related standard deviation for the limit of quantitation were well within the desirable limit of not more than $2.0 \%$. The lowest quantifiable concentration was $8.3 \mathrm{mcg} / \mathrm{mL}$ and this parameter can be used for predicting the drug release in low dose formulation.

\section{Conclusion}

The simple, sensitive, and inexpensive isocratic RP-HPLC method was developed and validated for the estimation of Losartan potassium in dissolution samples of immediate release and sustained release tablets. The dissolution study showed that Losartan potassium has good stability and the percentage of drug released was satisfactory for all the evaluated batches from the formulation. The validation results show that the method is specific, accurate, linear, precise, rugged, and robust. The run time is relatively short $(6.0 \mathrm{~min})$ which enables rapid quantification of many samples in routine analysis. Therefore this method is proposed for the quality control studies of Losartan potassium conventional and sustained release pharmaceutical dosage 
forms contributing to assuring the therapeutic efficacy of the drug.

\section{Conflict of Interests}

The authors declare that there is no conflict of interests regarding the publication of this paper.

\section{Acknowledgment}

The authors are thankful to Ultra College of Pharmacy, Madurai, for providing the laboratory facilities to carry out the present investigation.

\section{References}

[1] S. Azarmi, W. Roa, and R. Löbenberg, "Current perspectives in dissolution testing of conventional and novel dosage forms," International Journal of Pharmaceutics, vol. 328, no. 1, pp. 12-21, 2007.

[2] The United States Pharmacopoeia Drug Information, vol. 1, The United States Pharmacopoeia Convention, Rockville, Md, USA, 18th edition, 1998.

[3] S. B. Wankhede, K. C. Raka, S. B. Wadkar, and S. S. Chitlange, "Spectrophotometric and HPLC methods for simultaneous estimation of amlodipine besilate, losartan potassium and hydrochlorothiazide in tablets," Indian Journal of Pharmaceutical Sciences, vol. 72, no. 1, pp. 136-140, 2010.

[4] B. Pitt, R. Segal, F. A. Martinez et al., "Randomised trial of losartan versus captopril in patients over 65 with heart failure (Evaluation of Losartan in the Elderly Study, ELITE)," Lancet, vol. 349, no. 9054, pp. 747-752, 1997.

[5] K. E. McCarthy, Q. Wang, E. W. Tsai, R. E. Gilbert, D. P. Ip, and M. A. Brooks, "Determination of losartan and its degradates in COZAAR tablets by reversed-phase high-performance thinlayer chromatography," Journal of Pharmaceutical and Biomedical Analysis, vol. 17, no. 4-5, pp. 671-677, 1998.

[6] S. R. Sathe and S. B. Bari, "Simultaneous analysis of losartan potassium, atenolol, and hydrochlorothiazide in bulk and in tablets by high-performance thin-layer chromatography with UV absorption densitometry," Acta Chromatographica, no. 19, pp. 270-278, 2007.

[7] M. G. Quaglia, E. Donati, G. Carlucci, P. Mazzeo, and S. Fanali, "Determination of losartan and hydrochlorothiazide in tablets by CE and CEC," Journal of Pharmaceutical and Biomedical Analysis, vol. 29, no. 6, pp. 981-987, 2002.

[8] O. C. Lastra, I. G. Lemus, H. J. Sánchez, and R. F. Pérez, "Development and validation of an UVderivative spectrophotometric determination of Losartan potassium in tablets," Journal of Pharmaceutical and Biomedical Analysis, vol. 33, no. 2, pp. 175-180, 2003.

[9] R. M. Maggio, P. M. Castellano, and T. S. Kaufman, "A multivariate approach for the simultaneous determination of losartan potassium and hydrochlorothiazide in a combined pharmaceutical tablet formulation," Analytical and Bioanalytical Chemistry, vol. 391, no. 8, pp. 2949-2955, 2008.

[10] A. H. Prabhakar and R. Giridhar, "A rapid colorimetric method for the determination of Losartan potassium in bulk and in synthetic mixture for solid dosage form," Journal of Pharmaceutical and Biomedical Analysis, vol. 27, no. 6, pp. 861-866, 2002.
[11] D. L. Hertzog, J. F. McCafferty, X. Fang, R. J. Tyrrell, and R. A. Reed, "Development and validation of a stability-indicating HPLC method for the simultaneous determination of Losartan potassium, hydrochlorothiazide, and their degradation products," Journal of Pharmaceutical and Biomedical Analysis, vol. 30, no. 3, pp. 747-760, 2002.

[12] N. Erk, "Analysis of binary mixtures of losartan potassium and hydrochlorothiazide by using high performance liquid chromatography, ratio derivative spectrophotometric and compensation technique," Journal of Pharmaceutical and Biomedical Analysis, vol. 24, no. 4, pp. 603-611, 2001.

[13] G. Carlucci, G. Palumbo, P. Mazzeo, and M. G. Quaglia, "Simultaneous determination of losartan and hydrochlorothiazide in tablets by high-performance liquid chromatography," Journal of Pharmaceutical and Biomedical Analysis, vol. 23, no. 1, pp. 185189, 2000.

[14] R. C. Williams, M. S. Alasandro, V. L. Fasone, R. J. Boucher, and J. F. Edwards, "Comparison of liquid chromatography, capillary electrophoresis and super-critical fluid chromatography in the determination of Losartan Potassium drug substance in Cozaar tablets," Journal of Pharmaceutical and Biomedical Analysis, vol. 14, no. 11, pp. 1539-1546, 1996.

[15] S. A. Özkan, C. Akay, Ş. Cevheroglu, and Z. Şentürk, "Rapid and accurate simultaneous determination of fosinopril sodium and hydrochlorothiazide in tablets by HPLC," Journal of Liquid Chromatography and Related Technologies, vol. 24, no. 7, pp. 983-991, 2001.

[16] ICH, "Q2 (R1) validation of analytical procedure, test and methodology," in Proceedings of the International Conference on Harmonization, Geneva, Switzerland, 2005.

[17] ICH, Q2A. Validation of Analytical Procedures, Consensus Guidelines, ICH Harmonized Tripartite Guidelines, 1994.

[18] ICH, Q2B. Validation of Analytical Procedures: Methodology, Consensus Guidelines, ICH Harmonized Tripartite Guidelines, 1996.

[19] United States Pharmacopoeia, United States Pharmacopoeial Convention, Rockville, Md, USA, 31st edition, 2007.

[20] USP General Chapter on Dissolution, United States Pharmacopeia and National Formulary, United States Pharmacopeial Convention, Rockville, Md, USA, 2006.

[21] FDA Guidance for Industry: Dissolution Testing of Immediate Release Solid Oral Dosage Forms, US Department of Health and Human Services, Centre for Drug Evaluation and Research (CEDER), Food and Drug Administration, Rockville, Md, USA, 1997.

[22] ICH, “(Q2R1) Guideline on validation of analytical procedures: text and methodology," in Proceedings of the International Conference on Harmonization, Geneva, Switzerland, 2007.

[23] USP General Chapter on the Dissolution Procedure: Development and Validation, United States Pharmacopeia and National Formulary, United States Pharmacopoeial Convention, Rockville, Md, USA, 2006.

[24] "US Pharmacopeial Forum," Pharmacopoeial Previews, vol. 30, pp. 351-363, 2004.

[25] US Pharmacopoeia NF-25, The Dissolution Procedure: Development and Validation, US Pharmacopoeial Convention, Rockville, Md, USA, 32nd edition, 2009.

[26] C. K. Brown, H. P. Chokshi, B. Nickerson, R. A. Reed, B. R. Rohrs, and P. A. Shah, "Acceptable analytical practices for dissolution testing of poorly soluble compounds," Pharmaceutical Technology, vol. 28, no. 12, pp. 56-65, 2004. 
[27] G. Freitag, "Guidelines on dissolution profile comparison," Drug Information Journal, vol. 35, no. 3, pp. 865-874, 2001.

[28] K. E. McCarthy, Q. Wang, E. W. Tsai, R. E. Gilbert, D. P. Ip, and M. A. Brooks, "Determination of losartan and its degradates in COZAAR tablets by reversed-phase high-performance thinlayer chromatography," Journal of Pharmaceutical and Biomedical Analysis, vol. 17, no. 4-5, pp. 671-677, 1998. 

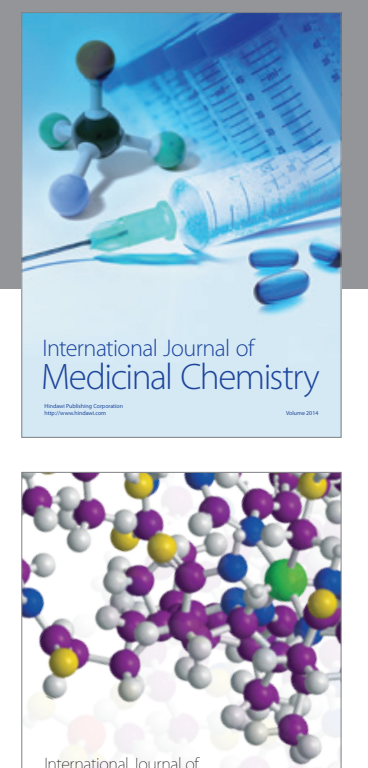

\section{Carbohydrate} Chemistry

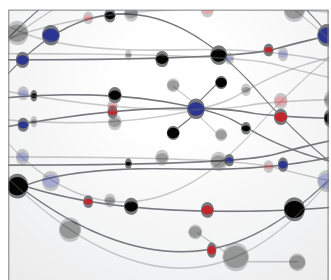

The Scientific World Journal
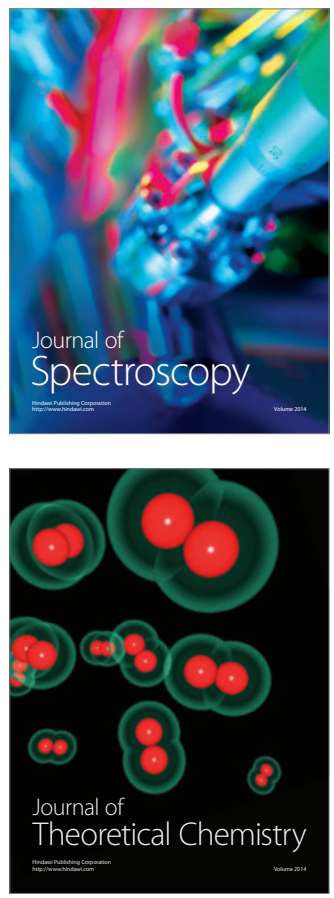
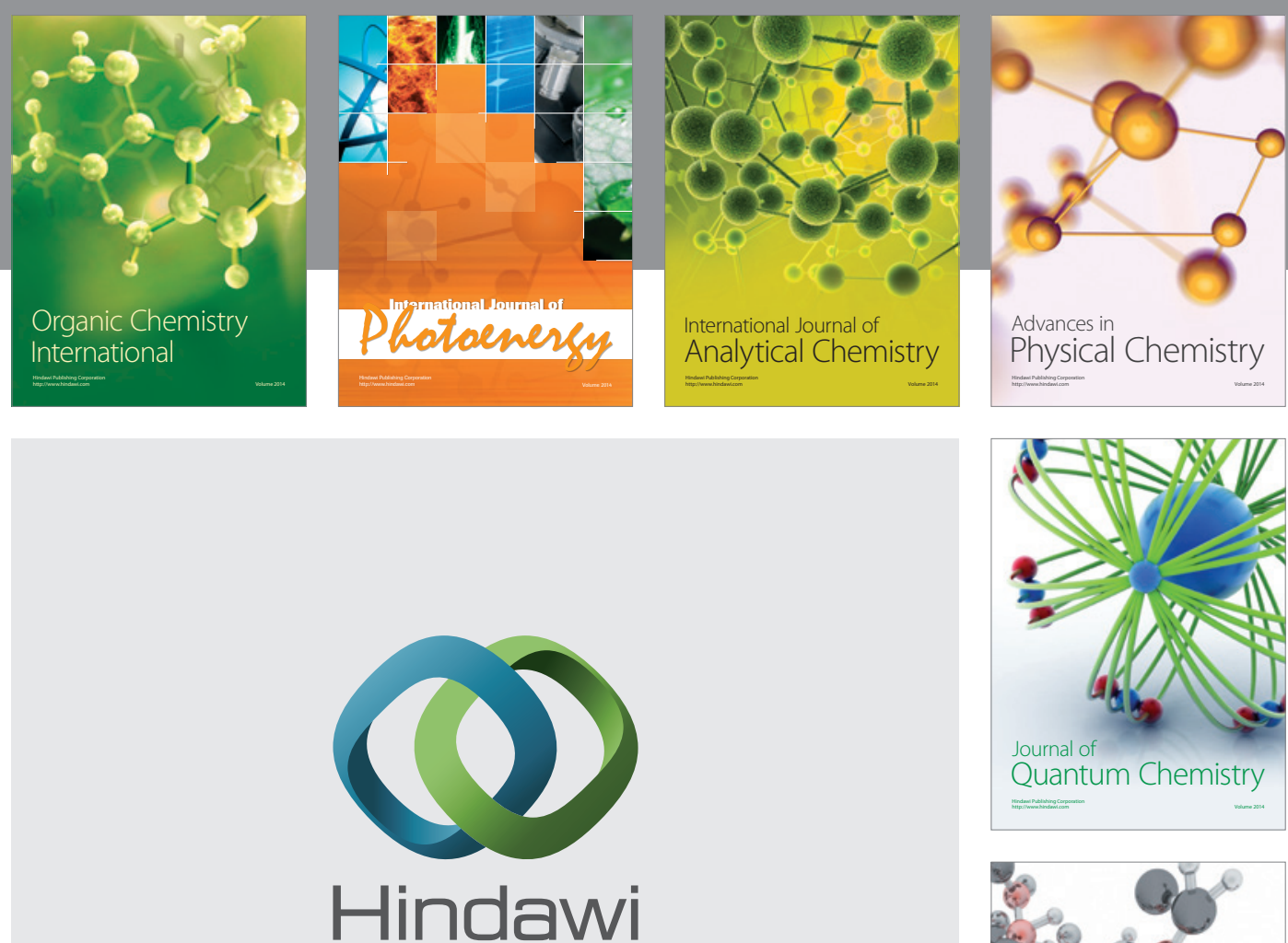

Submit your manuscripts at

http://www.hindawi.com

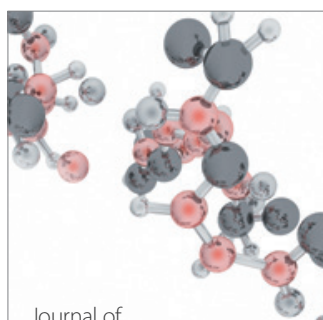

Analytical Methods

in Chemistry

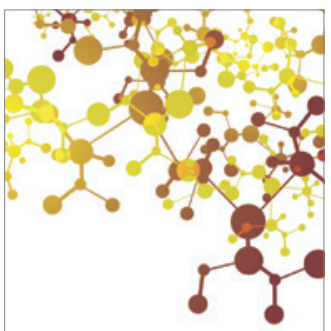

Journal of

Applied Chemistry

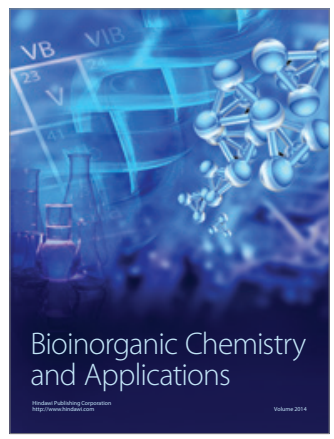

Inorganic Chemistry
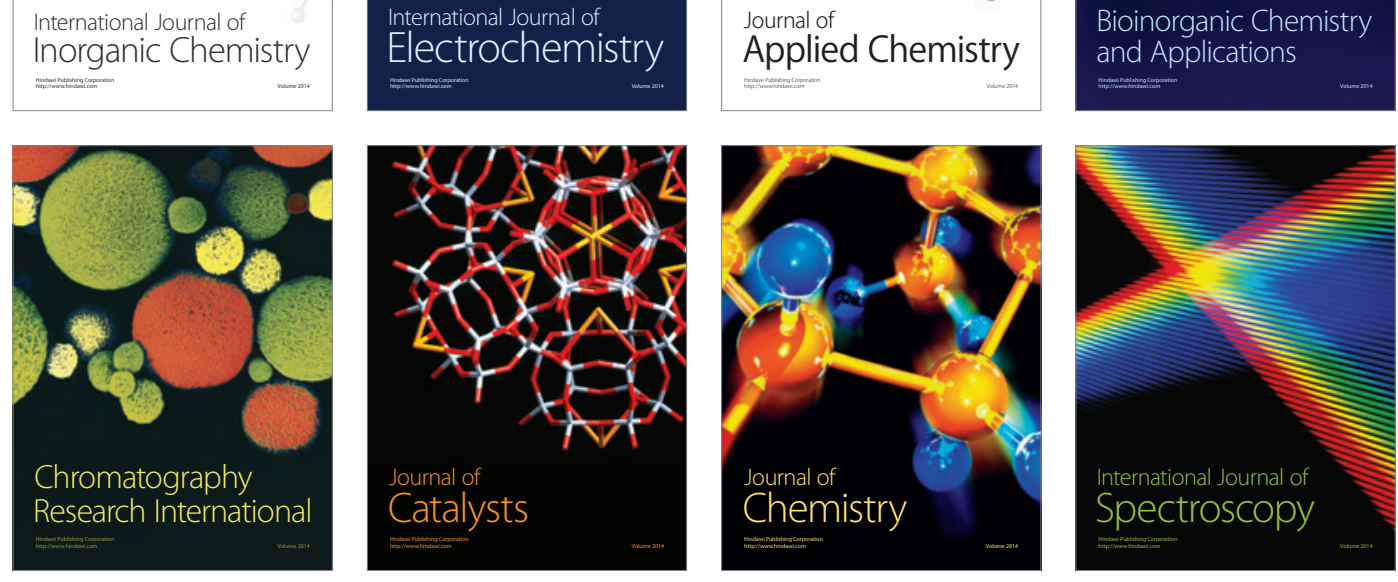